$\mathrm{V} \Delta \mathrm{K} 316.334 .3$

ББК 66.3(0), 4

DOI 10.22394/1682-2358-2020-5-57-66

V.A. Podolskiy, Candidate of Sciences (Politics), Docent of Political Sciences Faculty, State Academic University for the Humanities, Moscow

\section{COMPARING RUSSIAN AND US SOCIAL POLICY SYSTEMS}

A comprehensive comparison of Russian and American social policy systems is drawn. Social policy origins, organization, role of private sector and general efficiency of the systems are compared. Pension system, allowances and benefits, healthcare and education in Russia and the US are matched against each other, as well as their funding and functional features.

Key words and word-combinations: social policy, USA, Russia.
В.А. Подольский, кандидат политических наук, дочент факультета политологии Государственного академического университета гуманитарньх наук (email: deomniscibili@yandes.ru)

\section{СРАВНЕНИЕ СИСТЕМ СОЦИААЬНОЙ ПОАИТИКИ РОССИИ И США*}

Аннотация. Проводится комплексное сравнение систем социальной политики США и России. Сопоставляются происхождение систем, их организация, роль частного сектора и эффективность. Сравниваются пенсионная система, система пособий и льгот, система здравоохранения и система образования в России и США, их финансирование и особенности функционирования.

Ключевые слова и словосочетания: социальная политика, США, Россия.

B настоящее время в академической и политической сферах России ведется Аискуссия о том, какие количественные и качественные изменения необходимы в сфере социальной политики. В качестве одного из вариантов модернизации социамьной помитики в России преАлагается передать часть социамьных функций от государства бизнесу. Аیя изучения осо-

* Статья подготовлена при финансовой поддержке в рамках выполнения ГЗ (государственного задания) ГАУГН по теме «Современное информационное общество и цифровая наука: когнитивные, экономические, политические и правовые аспекты» (FZNF-2020-0014). 
бенностей работы системы соџиальной политики, опирающейся на частные финансы и институты, следует обратиться к американскому опыту.

Интерес к американской соџиальной политике в советской науке возник в 1970-е и сохранялся в 1980-е, было опубликовано множкество трудов с критическим анализом состояния американской соџиальной политики. В девяностые популярность проблемы значительно снижается. В нулевые и десятые годы опубликован ряд монографий, крупнейшие современные специалисты по американской соџиальной политике -

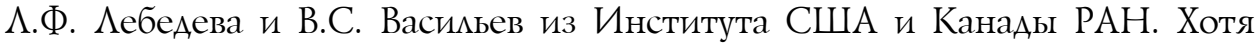
сравнению соџиальной политики США с Аругими странами Запада посвящено достаточно большое количество работ европейских и американских авторов, Ао сих пор сопоставцение всех элементов социальной политики в США и России не проводияось.

В Аанном исследовании сравниваются происхождение, организаџия и эффективность государственной системы соџиальной политики в России и американской соџиальной системы, в которой преобладает частный сектор. Сопоставляются пенсионная система, система пособий и мьгот, система зАравоохранения и система образования. Парамлемьное изучение соџиальной политики США и России преАставляет интерес Аля выявления сицьных и слабых сторон отечественной соџиальной поАитики.

В настоящем исследовании соџиальные расходы рассматриваются как вся совокупность трат из частных и государственных источников на пенсионное обеспечение, пособия, мьготы, образование и зАравоохранение.

Существуют два основных подхода к финансированию соџиальной политики: «подход Бисмарка», канџмера Германии, который ввел обязательное пенсионное страхование в 1880-е, и «подход Бевериджа», британского экономиста, чей доклаА в 1940-е поскужиц основанием дия создания государственной системы зАравоохранения и всеобщего пенсионного обеспечения. Немеџкий принщип соџиального страхования вырос из практик гильдий и торговых городов по защите своих членов и граждан от нужды и несчастных скучаев из среАств обшего фонда, куда чмены гильдий делали страховые взносы. Британский принџип социального обеспечения восходит к расширенному прочтению законов о бедных, согласно которым государство должно гарантировать, что никто из жителей страны не будет голодать, а оплата соџиальных расходов производится из налогов. В США преобцадает первый принџип, причем в

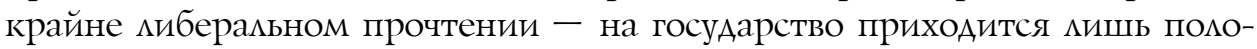
вина соџиальных расходов. В России до 1950-х также действовала система Бисмарка, но всеобщее пенсионное обеспечение приблизило отечественную систему к британской, хотя ряд элементов соџиальной политики реализован в России на основании страхового принципа. 
Американская государственность ведет отсчет с 1776 г., но помощь нуждающимся была организована еще в колониальную эпоху. В XVII в. английские законы о бедных появились на континент вместе с прибывшими посеменцами. В основном правика той эпохи предусматриваци сбор и предоставление помощи нуждающимся семьям на местном уровне, когда плательщики и получатели были мично знакомы межАу собой [1, с. 19-24]. Помошь нуждающимся в США предоставмялась также религиозными организаџиями - сначала протестантскими деноминаџиями, а с XIX в. и католической церковью, создавались образовательные и медицинские учреждения, многие из них функционируют и по сей день. Благотворительность и сегодня играет в Америке заметную роль, достигая около 2\% ВВП [2, с. 21].

В России христианская благотворительность была организована церковью с XI в. У монастырей и храмов нуждающимся предоставлялась еда и деньги, также устраивались богадельни, в которых бедные могли получить медицинские услуги или приют [3, с. 28]. В XIX веке массовым феноменом стали церковно-приходские школы [4, с. 134], при подлержке госуАарства были созданы тысячи благотворительных организаций. Расходы на бцаготворительность в России в наши дни составцяет не более 0,3\% ВВП $[5$, c. 8$]$.

Пенсионная система в России начала формироваться раньше, чем в США: моряки получици право на пенсию еще в начале XVIII в., а в середине столетия это право распространимось на военных и госслужащих [6, с. 21-36] . В конџе XVIII столетия в США вводят пособия Амя потерявших трудоспособность в войне за независимость сомдат и пенсии Амя служащих военноморского фмота [7, с. 63]. При этом государственные законы появицись иишь через двадцать мет после распространения практики [1, с. 41].

В XIX в. пенсионная система развивается в обеих странах соизмеримыми темпами. В первые десятилетия право на пенсию получают ветераны войны за независимость в США [7, с. 126], а в России создается первый пенсионный фонд Аця содержания вдов государственных служащих [6, с. 58]. Во второй половине века в России возникают эмеритальные кассы дмя государственных органов, в которые сотрудники отчисляли АОлю от зарплат - выплачиваемые из них пенсии были призваны дополнять государственные пенсии, предоставляемые за счет казны [6, с. 78] . В США первыми получателями пенсий стали полиџейские; средства в их фонА поступали из штрафов, денег от продажи арестованного имущества. Некоторые промышиенные и транспортные компании Америки стали предоставмять своим сотрудникам пенсии в конце XIX в., а пенсии дмя госслужащих появились в 1910-е годы на уровне штатов и в 1920-е на уровне федерации $[8$, с. $84-85]$.

В России государственные пенсии по инвалидности дмя рабочих стали появцяться в начале XX в., число их получателей было существенно рас- 
ширено в первые десятияетия советской власти, а в 1920-е годы введена пенсия по старости [3, с. 94]. В США отдельные штаты преАпринимали попытки создать систему пенсионного обеспечения дмя пожилых и нетрудоспособных граждан еще в 1910-е годы, но на общегосударственном уровне система взносов с зарплат и выплаты пенсий по старости и инвамидности быма введена кишь при Ф.А. Рузвельте в 1935 г. [1, с. 225-230] . Баланс фондов, из которых должны были производиться выплаты пенсионерам, рассчитывался на 75 мет впереА. В самом основании американской системы пенсионного обеспечения заложен принцип долгосрочного планирования, который можно считать одной из наиболее џенных идей, подходящих Аля рецепџии в российской практике [9, с. 24].

В 1970-е годы государство поддержало негосударственные пенсионные фонды с помощью налоговых мьгот при покупке ценных бумаг их участниками [10, с. 282]. В этот же период были введены пенсии дяя малоимущих, финансируемые из налогов, а также задействованы многочисленные пенсионные программы на уровне штатов.

Всеобщее пенсионное обеспечение в России бымо введено в 1956 г.,

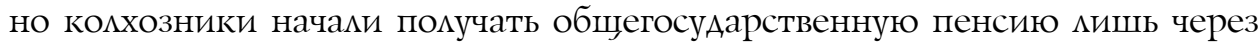
десятиметие [3, с. 80-81].

И Россия, и США сталкиваются с проблемой дефиџита пенсионных фондов, при этом в России дефицит острее - выплаты из пенсионного фонда страны превышают поступления страховых взносов на 50-100\%; недостающие соџиальные средства выдемяются из бюджета $[11$, с. 66]. В США наиболее существенный дефицит испытывают частные фонды с установленными выплатами, в которых пенсии превышают взносы на $30 \%$ [12, с. 2-3], и фонды штатов, гАе взносы на 20\% меньше, чем пенсии $[13$, c. 20]. Общая сумма дефицита при этом остается сравнительно незначительной и составляет около $10 \%$ от суммы страховых взносов всех программ пенсионного обеспечения.

Пенсионные отчисления граждан и взносы на страховку от безработиџы в США в общей сложности составмяют около четверти заработной платы, эта сумма обычно делится поровну с работодателем. 12\% выплачивается на государственную пенсию, еше около $1 \%$ идет на страховку от безработицы, около $11 \%$ составцяют взносы в частные пенсионные планы и программы штатов [14, с. 4].

В России отчисления в пенсионный фонА составцяют $22 \%$ от заработных плат, а на сощиальное страхование направляется еще почти 3\% [15, с. 114] , то есть итоговая сумма фактически совпадает. Аефицит пенсионного фонда в России обусловлен опережающим ростом пенсионных выплат в последние десятилетия (зарплаты с 2000 по 2018 г. выросли в 16 раз, а пенсии - в 23 раза) [16, с. 157] и разницей в пенсионном возрасте (в США граждане выходят на пенсию в 65 мет с самого начала действия закона о пенсионном страховании). 
Государственные пенсии в России составляют около 8\%, а частные пенсии не Аостигают и 0,1\% ВВП [16, с. 157-159]. В США выплаты государственных пенсий составмяют примерно 5\% ВВП [17, с. 407], а негосударственных $-4 \%[12$, с. 2] .

Страхование от безработицы появилось в России после революции, но уже через четырнадџать мет страна перешла к режиму всеобщей занятости, и биржи труда были упразднены вплоть до 1991 г. когАа пособия по безработице были восстановлены [3, с. 36-48] .

В США с 1930-х годов штаты начали создавать страховые программы Аля решения проблемы безработиџы. В 1935 г. была введена федерамьная страховка от безработиџы, в 1930-е же годы федеральным правительством были организованы общественные работы [1, с. 275-280]. По сей день в стране сосушествуют страховые схемы штатов и федеральная страховка.

В США значительно шире, чем в России распространена практика намоговых цьгот. В Америке налоговые кредиты предоставцяются семьям с Аетьми, на заработанный доход при оплате медицинской страховки, при участии в пенсионных схемах. Общая сумма налоговых кредитов в США составляет порядка 3\% ВВП [18, с. 20-30]. В России наиболее распространенные налоговые мьготы дмя граждан - имущественные, например, при покупке жилья, но также предоставцяются вычеты по цечению, образованию и пенсионным взносам. Их общая сумма существенно уступает объему налоговых кредитов в Америке и составляет порядка 0,2\% ВВП $[19$, c. 103]

И штаты, и регионы обладают большими полномочиями в сфере социальной политики. В России на региональные бюджеты можится существен-

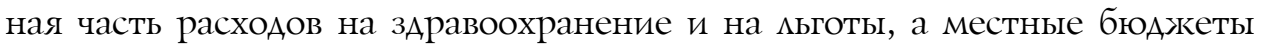
платят за образование [16, с. 538]. В США местные бюджеты платят за среднее образование, а на штаты приходится значительная доля расходов на высшее образование. Штаты также тратят в общей сложности более $2 \%$ ВВП на размичные соџиальные программы [20].

Все льготы штатов [20] и федераџии [21, с. 35-38] обходятся бюАжетам в 3\% ВВП в США, анацогичную долю валового продукта составмяет сумма расходов России на иьготы и пособия [16, с. 157]. Наиболее крупные программы в США - талоны на питание и еАа Аця малоимущих женщин и детей, школьные завтраки и обеды (0,5\% ВВП), образовательные программы и программы переподготовки (0,5\% ВВП), программы субсидий на приобретение жилья и оплату коммунальных услуг $(0,1 \%$ ВВП) [21, с. 35-38] . В России самые крупные статьи расходов - это семейные и материнские пособия (0,7\% ВВП), субсидии оплаты услуг ЖКХ (0,3\% ВВП), закупка $ь$ ьотных мекарств $(0,1 \%)$ [16, с. 159], существенную роль играет также мьготный проезА на транспорте. 
Земская медищина в России второй половины XIX в. охватывала чрезвычайно незначительную долю населения страны, но сама система, в отмичие от американской частной медицины, теоретически предусматривала возможность получения соџиальных услуг всеми жителями на бесплатной основе. Целостная система зАравоохранения в России была создана в первые годы правления большевиков поА руководством народного комиссара РСФСР Н.А. Семашко. На момент учреждения советская медицина была передовой с точки зрения организационной архитектуры и номинальной доступности - это была первая в мире всеобщая система бесплатной меАиџины [22, с. 367-371].

В США благотворительные организации оплачивают медицинские услуги с XVII в., гражданам также гарантирована помощь в экстренных ситуациях. В 1950-е годы была создана государственная программа медиџинской страховки дмя военнослужащих, а в 1965 г., при Аиндоне Ажонсоне, - «Медикейр» Аця пожилых и «МедикейА» Аля малоимущих граждан [1, с. 313-327]. Система зАравоохранения чрезвычайно разАроблена с организационной точки зрения; например, государственная программа «Медикейр» объединяет четыре программы - стационарного, амбулаторного мечения, мекарственного обеспечения и частные страховые программы. Потребители программы «МедикейА" сталкиваются с завышенными ценами и отказами в обслуживании, поскольку страховка дця малоимущих предполагает сравнительно низкие выплаты Аля медиџинских учреждений [23 с. 153]. Если в России вероятность банкротства семьи из-за меАиџинских расходов невелика, то в США 60\% мичных банкротств связано с оплатой счетов за мечение [23, с. 308].

Величина взносов на обязательное медиџинское страхование в России составляет $5 \%$ от заработной платы $[15$, с. 114]. В США отчисления граждан и работодателей на «Медикейр» с заработной платы составляют 3\%, но подпрограммы требуют дополнительных платежей от граждан [23, с. 110-112]. Взносы граждан в ОМС обеспечивают Ао половины всех соџиальных расходов на здравоохранение в стране [24, с. 342], а на «МеАикейр» приходится мишь 1/5. Программа медиџинского страхования Аля нужАающихся граждан «Медикейд» финансируется из бюджетов федерации и штатов и стоит приблизительно столько же, сколько и программа «Медикейр» [17, с. 407].

Расходы на здравоохранение в США втрое выше, чем в России, и составмяют $18 \%$ ВВП (9,5\% - частные, $8,5 \%$ - государственные) [25, с. 12] против $5 \%$ (1,5\% - частные, $3,5 \%$ - государственные) [24, с. 339]. При этом эффективность системы опережкает российскую на треть при измерении по такому показателю, как «бремя болезней», то есть годы жизни, скорректированные по нетрудоспособности, 42 против 30 тысяч на 100 тысяч [26]. 
Становление системы образования США произошио раньше, чем в России. Первые бесплатные школы в Америке появились еще в середине XVII в., а в 1850-е годы бесплатное государственное образование стало законом [4, с. 129]. В России полноценная система школьного образования была создана только после Октябрьской революции, а первые государственные школы появицись в 1780-е годы под эгидой приказов общественного призрения [3, с. 33] .

Расходы на среднее образование в США несколько выше, чем в России: $4 \%$ ВВП тратится на школы в США (0,5\% из них - частные) [27, с. 112-1119], поряака 2,5\% - в России [28, с. 11]. Согласно рейтингу МежАународной программы по оџенке образовательных достижений учащихся Организации экономического сотрудничества и развития США опережает Россию на $3 \%$ по среАнему рейтингу. Аидеру рейтинга, Китаю, США уступает примерно на 15\% [29, с. 16-17].

Высшие учебные заведения в США стали появляться в XVII в., раньше, чем в России: Гарвард был учрежден в 1636 г. [4, с. 104], а Славяно-ГрекоАатинская академия - в 1687 г. [4, с. 80-81]. Образование в высших учебных заведениях в России было преимущественно платным вплоть до 1950-х годов, но в первые десятицетия советской власти пцата оставацась сравнительно низкой и составмяла около одной месячной зарплаты за гоА обучения [30]. Сегодня в России 2/3 студентов обучаются за счет бюджета [16, с. 201], в США треть студентов получают федеральные гранты дАя оплаты части стоимости образования [27, с. 187].

Высшее и среднее профессиональное образование получают в США гораздо больше ресурсов, чем в России: $3 \%$ (1\% из них - частные) [27, с. 174-179] против $1 \%$ ВВП (частные - 0,2\%) [28, с. 11]. Результаты США гораздо выше - 40\% университетов в топ-100 высших учебных заведений рейтинга Times - это американские университеты, российские университеты в топ-100 не входят, МГУ имени М.В. Аомоносова в 2019 г. занял 199-е место [31, с. 18-19]. Аия США характерна не встречающаяся в России и Европе проблема, а именно большие суммы студенческого АОлга, связанные с высокой стоимостью обучения, соизмеримой с годовой заработной платой [32].

Система дошкольного образования в России получает примерно столько же средств, как и в США [27, с. 15-18]: расходы составцяют около 0,6\% ВВП (в России частные - 0,2\%, в США - 0,3\%) [28, с. 11] . Аоля детей в детских садах соизмерима и составмяет примерно $2 / 3$ от общей численности детей [16, с. 87].

Сравнение важнейших элементов соџиальной политики в России и в США позволяет сделать ряд выводов о ключевых особенностях систем, могике их организаџии и общей эффективности. Исторический обзор свидетельствует, что, хотя системы формировались сопоставимыми темпами, американская и российская системы образования кардинально разцича- 
ются по своему происхождению, роли государства, организаџии. В США мокальные инициативы становились федеральными практиками. Местные власти не справлялись с расходами на социальную политику и запрашивали помощь у вмастей штатов, затем у центральных вмастей [1, с. 88]. Социальная политика эволюционировала из программ частных корпораций, местных сообществ, а также предприятий и энтузиастов в сфере благотворительности, а государство со временем вводицо регулирование Амя соблюдения участниками рынка правия игры. Мера доступных благ определялась условиями контракта с работодателем.

В России система была создана џерковью, распоряжениями монархов и постановлениями Совета народных комиссаров. Инициатива при-

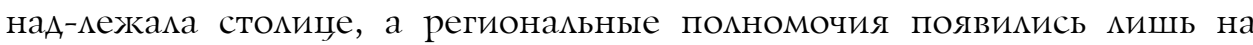
позАних этапах становления системы. В Российской империи и в первые десятилетия советской власти предоставление помощи зависело от принадлежности к организащии. У преАприятий существовали свои больничные кассы и медучреждения, страховые, пенсионные фонды, в советские годы - свои образовательные, медиџинские, спортивные и культурные учреждения. Фонды были объединены еще в самом начале существования СССР, а медицинские учреждения стали переходить с производственного на территориальный принџип обслуживания в 1940-е годы; переподчинение детских садов и школ муниџипалитетам началось

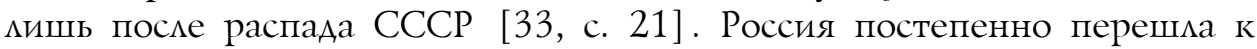
британской, всеобщей модели.

Страховые взносы граждан в США обеспечивают финансирование $90 \%$ пенсионной системы и 4/5 системы зАравоохранения. Из федерального и региональных бюАжетов оплачиваются программы с проверкой на нуждаемость, в первую очередь это предоставление талонов на еду и оплата образования. Аоступность благ увеличивают налоговые мьготы. В России взносы граждан обеспечивают до половины финансирования системы заравоохранения и пенсионной системы. Из федерального и региональных бюджетов выплачиваются семейные пособия, субсидируется ЖКХ и транспорт. Аоступность бцаг увемичивают пособия и беспиатные услуги.

Сопоставление Авух систем позволяет выявить ряд важных уязвимостей отечественной социальной политики. Во-первых, это проблема наполнения пенсионного и медицинского фондов. Из-за того, что Россия фактически использует систему соџиального обеспечения по БевериАжу, опираясь на структуры, выстроенные в страховой цогике Бисмарка, страховых взносов не хватает, и недостающие среАства выплачиваются в фонды напрямую из бюджетов. США удается избегать дефиџита фондов благодаря индексации взносов. Во-вторых, это возраст получения доступа к соџиальным благам, который изначально снижац нагрузку на фонды: и пенсии, и государственная медиџинская страховка «Медикейр» предо- 
ставляются гражданам США с 65 мет. В-третьих, это качество зАравоохранения и образования: фактор конкуренции за клиента, побуждающий американские вузы улучшать уровень образования, а учреждения зАравоохранения обновцять оборудование, в России присутствует в значительно меньшей мере.

Стоимость российской системы, измеренной как доли от внутреннего валового продукта, почти вдвое ниже, чем американской (около 20 и $35 \%$ ВВП соответственно); при этом относительная доступность соџиальных благ в России выше. Во всех странах во все времена смысл соџиальной политики состоит в том, чтобы обеспечить устойчивость государства, гарантировав населению страны прожиточный минимум, адекватный Аля Аанной эпохи и территории. Следовательно, можно утверждать, что по общей эффективности российская система опережает американскую, а привлечение частного сектора в сферы, где возможности для извлечения прибыли заведомо ограничены ици отсутствуют, оказывается менее выГОАНЫМ.

\section{Библиографический список}

1. Trattner W.I. From poor law to welfare state: a history of social welfare in America. 5th ed. N.Y.: The Free Press, 1994.

2. Giving USA 2019: The Annual Report on Philanthropy for the Year 2018. Indianapolis: Lilly family school of philanthropy, 2019.

3. Лушникова М.В., Лушников А.М. Курс права социального обеспечения. 2-е изд., доп. M., 2009.

4. Джуринский А.Н. История образования и педагогической мысли: учебник для студ. высш. учеб. заведений. М., 2003.

5. Шпак A.B. [и др.]. Российский филантроп: важность личного доверия к исполнителям и ожидание конкретных результатов. М., 2018.

6. Гусаков Д.Б. Генезис государственного пенсионного обеспечения и социального страхования в Российской империи: историко-правовой аспект: дис. ... канд. юрид. наук. СПб., 2015.

7. Clark R.L., Craig L.A., Wilson W.J. A History of Public Sector Pensions in the United States. Philadelphia: University of Pennsylvania Press, 2003.

8. Hewitt W.H. Lateral Entry and Transferability of Retirement Credits. Washington: President's Commission on Law Enforcement and Administration of Justice, 1967.

9. Васильев В.С. США: опыт социальной политики и уроки для России. М., 2007.

10. The Oxford Handbook of U.S. social policy / ed. by D. Beland, C. Howard, K.J. Morgan. N.Y.: Oxford University Press, 2015.

11. Седова М.Л. Сбалансированность бюджета пенсионного фонда России и проблемы финансовой устойчивости пенсионной системы // Известия СПбГЭУ. 2018. № 5 (113). C. 64-70.

12. Private Pension Plan Bulletin, September 2019. Washington: Employee Benefits Security Administration, United States Department of Labor.

13. The State Pension Funding Gap: 2017 // The PEW Charitable trusts. June 2019. 
14. Martin P.P., Weaver D.A. Social Security: A Program and Policy History // Social Security Bulletin. 2005. Vol. 66, No. 1. P. 1-15.

15. Филипповская O.В. Эволюция страховых взносов государственных внебюджетных фондов России // Инновационная экономика: перспективы развития и совершенствования. 2016. № 3 (13). С. 112-116.

16. Российский статистический ежегодник, 2019. М., 2019.

17. Лебедева Л.Ф. Перспективы финансирования социальных программ в США // Финансовая аналитика: проблемы и решения. 2018. Т. 11, вып. 4. С. 401-414.

18. Estimate of Federal Tax Expenditures for Fiscal Years 2019-2023. Washington: Joint Committee on Taxation, December 2019.

19. Развитие эффективной социальной поддержки населения в России: адресность, нуждаемость, универсальность: научный доклад / под ред. В. Назарова, А. Пошарац. M., 2017.

20. Annual Survey of State and Local Government Finances. Suitland: United States Census Bureau, 2020.

21. Rector R., Menon $V$. Understanding the Hidden $\$ 1.1$ Trillion Welfare System and How to Reform It // Backgrounder. 2018. April 5, No. 3294. The Heritage Foundation.

22. Большая медицинская энциклопедия: в 30 т. 3-е изд. / гл. ред. Б.В. Петровский. M., 1978. T. 8.

23. Rice T., Rosenau P., Unruh L.Y., Barnes A.J., Saltman R.B., van Ginneken E. United States of America: Health system review. Health Systems in Transition, 2013; 15(3) - European observer on health systems and policies.

24. Перхов В.И., Люико В.В. Макроэкономические расходы на здравоохранение в России и за рубежом // Современные проблемы здравоохранения и медицинской статистики. 2019. № 2. C. 334-344.

25. Hartman M., Martin A.B., Benson J., Catlin A. National Health Care Spending In 2018: Growth Driven By Accelerations In Medicare And Private Insurance Spending // Health Affairs. 2020. Vol. 39, No. 1. P. 8-17.

26. Global, regional, and national disability-adjusted life-years (DALYs) for 359 diseases and injuries and healthy life expectancy (HALE) for 195 countries and territories, 1990-2017: a systematic analysis for the Global Burden of Disease Study 2017 // The Lancet. 2018. 8 Nov.

27. Hussar B. [et al.]. The Condition of Education 2020 (NCES 2020-144). Washington: U.S. Department of Education, National Center for Education Statistics, 2020.

28. Клячко Т.Л., Токарева Г.С. Прогнозирование потребности в бюджетных средствах при реализации реформ в системе образования: научный доклад. М., 2017.

29. PISA 2018 Results. Combined executive summaries volume I, II \& III. Paris: OECD, 2018.

30. Кораблёва Г.В. Реализация принципов доступности и бесплатности образования в советском государстве (1917-1991 гг.) // Известия Самарского научного центра Российской академии наук. 2009. Т. 11, № 6(2). С. 341-345.

31. The World University Rankings // Times Higher Education. July 2019.

32. Cadaret M.C., Bennett S.R. College Students' Reported Financial Stress and Its Relationship to Psychological Distress // Journal of College Counseling. October 2019. Vol. 22. P. 225-239.

33. Советская социальная политика: сцены и действующие лица, 1940-1985 / под ред. Е.Р. Ярской-Смирновой, П.В. Романова. М., 2008. 